\title{
First report of microalgae Rhexinema paucicellulare (Ulvophyceae) in Mauritius and its biochemical evaluation as a source of fatty acids
}

\author{
Ritesh Bhagea, Vishwakalyan Bhoyroo, Daneshwar Puchooa \\ Agricultural and Food Science Department, Faculty of Agriculture, University of Mauritius, Réduit, Mauritius
}

\begin{abstract}
Mauritius is a tropical island with a very rich biodiversity of endemic organisms with an unexplored pool of microalgae, especially in the Ulvophyceae class. From freshwater sources, an isolate was characterised using morphological traits and $18 \mathrm{~S}$ rDNA region. It was determined to be Rhexinema paucicellulare and was further evaluated for its biochemical content against commercially available Spirulina sp. This study evaluates the lipids content and offers a first report on the carbohydrate and protein contents of this species. The biochemical profile of Spirulina sp. differed significantly from $R$. paucicellulare with respect to carbohydrate (17.36\% vs. $20.31 \%)$; protein $(45.09 \%$ vs. $25.71 \%)$ and lipids (5.86\% vs. $13.88 \%)$. Further exploration of the fatty acids profile
\end{abstract}

Correspondence: Ritesh Bhagea, Agricultural and Food Science Department, Faculty of Agriculture, University of Mauritius, Réduit 80837, Mauritius.

Tel: +230.403.7652; Fax: +230.465 .5743 .

E-mail: ritesh.bhagea@gmail.com

Key words: Ulvophyceae; Rhexinema; biochemical content analysis; fatty acids; microalgae.

Acknowledgements: The authors are thankful to the technical staff of the Agricultural and Food Science Department, University of Mauritius, for their assistance in this study and the staff of the National Environmental Laboratory (Ministry of Environment, Solid Waste Management and Climate Change) for GC/MS analysis.

Authors' contributions: All authors contributed equally to this work.

Further information: Funds for this project were provided by the University of Mauritius under the vote Q0193.

Conflict of interest: The authors declare no conflict of interest.

Received for publication: 3 July 2021.

Revision received: 10 January 2022.

Accepted for publication: 13 January 2022.

${ }^{\text {CC }}$ Copyright: the Author(s), 2022

Licensee PAGEPress, Italy

Journal of Biological Research 2022; 95:9950

doi:10.4081/jbr.2022.9950

This article is distributed under the terms of the Creative Commons Attribution Noncommercial License (by-nc 4.0) which permits any noncommercial use, distribution, and reproduction in any medium, provided the original author(s) and source are credited. through GC analysis revealed high presence of alpha-linolenic acid at $26.48 \%$ and linoleic acid at $6.31 \%$. The presence of important omega-3 FA was evidenced through GC/MS analysis with eicosapentaenoic acid and docosahexaenoic acid, which could make this isolate a potential candidate in the field of aquaculture.

\section{Introduction}

Mauritius is a tropical island with a very rich biodiversity of native and endemic organisms. Several of them have been studied for their biochemical content with the potential for exploitation in various economic sectors such as pharmaceutics. ${ }^{1}$ However, it is not the same case for microalgae, which represent a very promising source of amino acids, proteins, lipids, essential fatty acids, carbohydrates and secondary metabolites. ${ }^{2}$ Their culture in Mauritius is limited to few organisations such as the Albion Fisheries Research Centre, which cultures Nannochloropsis sp. and Chaetoceros calcitrans (both imported from Japan) for aquaculture practices and Green Create Nutra, which cultures Spirulina $\mathrm{sp}$. (of foreign origin) as a nutraceutical product and as feed additives. The culture of local microalgae for commercial application remains inexistent. Although a few research have been carried out, they mostly covered aspects of identification and population density evaluations with cyanobacteria, dinoflagellates and diatoms being dominant species. ${ }^{3,4}$ Therefore, based on these findings, other classes such as Ulvophyceae have been left completely unexplored.

This class of algae is globally dominated by marine species but recent studies have shown the occurrence of filamentous and sarcinoid freshwater species. The taxonomic positioning of some freshwater ulvophytes is, however, unstable based on recent research and revisions that emerged. A specific case of taxonomic instability is with the genus Rhexinema, in which Helicodictyon and Pleurastrum sarcinoideum would fall into, along with two new species $R$. edaphica and $R$. sancta-tomeai. ${ }^{5}$ This claim is currently refuted due to a lack of type species for Pleurastrum and the new species being phylogenetically unrelated to the type species of Rhexinema paucicellulare. ${ }^{6}$

The stability of taxonomic nomenclature is important especially when species or strains of microalgae are cultured with the intention of commercialisation. As part of an investigation of the Mauritian microalgal biodiversity for commercial use in aquaculture practices, we describe here the phylogenetic and biochemical characterisation of an isolate from the genus Rhexinema (Ulvophyceae), isolated from freshwater sources. The carbohydrates, protein, lipids and fatty acid profiles were experimentally compared to locally commercialised Spirulina sp., as a means to evaluate the possible applications of the isolate. 


\section{Materials and Methods}

\section{Sample collection, culture and morphological identification}

Water samples were collected from Midlands Dam (MD) reservoir by filtering $50 \mathrm{~L}$ of water through a $5 \mu \mathrm{m}$ mesh net. For inoculation, $100 \mu \mathrm{L}$ of sample was aseptically spread on Bold's Basal Medium (BBM) agar. The plates were incubated in a culture room with a light intensity of $\sim 50 \mu \mathrm{mol}$ photons $\mathrm{m}^{-2} \mathrm{~s}^{-1}$ at $24^{\circ} \mathrm{C}$ with a photoperiod of 14:10 hours (light:dark) for 14 days and then inoculated in $200 \mathrm{~mL}$ BBM supplied with filtered air at a rate of $10 \mathrm{~L} / \mathrm{min}$. The cultures were allowed to mature for 10 days before initiating microscopic analysis for cellular measurements of 100 cells (along length and width).

\section{DNA extraction and PCR amplification}

DNA extraction was done using a protocol devised for microal$\mathrm{gae}^{7}$ after 10 days of culture to ensure cells are harvested before the lag phase the growth pattern and free from contaminants. Due to unfavourable results obtained in initial trials with the original protocol, modifications were introduced, such as replacing TE buffer with CTAB buffer (2\% CTAB, 2\% PVP, $1.4 \mathrm{M} \mathrm{NaCl}, 0.2 \%$ 2-mercaptoethanol, $20 \mathrm{mM}$ EDTA, $100 \mathrm{mM}$ Tris-HCI, $\mathrm{pH} 8.0$ ) at the lysis step. The PCR analysis was performed using the primers P45 (5'ACCTGGTTGATCCTGCCAGT-3') and P47 (5'-TCTCAGGCTCCCTCTCCGGA-3') for the amplification of the region $18 \mathrm{~S} \mathrm{rDNA}{ }^{8}$ Successful amplicons were sequenced and then compared on NCBI BLASTn (https://blast.ncbi.nlm.nih.gov/Blast. cgi) against reference strains. The sequence was submitted under the accession number MT632094.1 in GenBank NCBI.

\section{Phylogenetic analysis}

The closest sequences obtained for the isolates from BLASTn for the $18 \mathrm{~S}$ gene were retrieved from GenBank (NCBI). Multiple sequence alignments were performed online using the MAFFT web server (version 7), ${ }^{9}$ and then manually cleaned using the software MEGA 6.06 (build 6140226). The evolutionary models that fit best for the analysis were calculated using the program JModelTest (v2.1.10 v20160303). ${ }^{10}$ The best model generated from the program was then selected using the Akaike Information Criterion (AIC).

For the phylogenetic analysis, the Maximum Likelihood (ML) method and Bayesian inference (BI) were used with the programs PhyML 3.0 and MrBayes 3.2.7, respectively. ${ }^{11,12}$ The model "GTR+I" was selected with the following parameters: nucleotide frequencies $\mathrm{A}=0.2741, \mathrm{C}=0.2001, \mathrm{G}=0.2296, \mathrm{~T}=0.2962$; substitution rates $\mathrm{AC}=0.2251, \mathrm{AG}=1.8029, \mathrm{AT}=1.0000, \mathrm{CG}=0.2251, \mathrm{CT}=1.8029$, $\mathrm{GT}=1.0000$ and P-invar $=0.56204$. Bootstrap support was calculated with 1000 replicates. For MrBayes, the evolutionary model GTR+I was used with 3,000,000 generations and a Markov Chain Monte Carlo sampling at a rate of 100. The Maximum Parsimony (MP) was performed using the software PAUP* v.4.0a and the Neighbour Joining (NJ) analysis were performed in MEGA 6.06.

\section{Biomass production}

The isolate, designated as strain MD1, was mass cultured with $\mathrm{BBM}$ in three $5 \mathrm{~L}$ plastic bottles under a light intensity of $64.17 \pm 7.50 \mu \mathrm{mol}$ photons $\mathrm{m}^{-2} \mathrm{~s}^{-1}$. The culture was supplied with air, at a rate of $6 \mathrm{~L} / \mathrm{min}$ filtered through a $0.2 \mu \mathrm{m}$ filter, and was exposed to a photoperiod of 14:10 hours (light:dark) at room temperature $\left(27-29^{\circ} \mathrm{C}\right)$ for a period of 22 days. The culture growth was measured through spectrophotometric analysis at $680 \mathrm{~nm}$ every 24 to 48 hours. ${ }^{13}$ The values were recorded in triplicate for statistical analysis. The biomass was harvested and oven-dried for 24 hours at $80^{\circ} \mathrm{C}$, ground to powdered form and stored at $4^{\circ} \mathrm{C}$ for further use..$^{14}$

\section{Biochemical analysis of biomass}

To compare the carbohydrate, protein and lipids content of isolate MD1, powdered Spirulina sp. was purchased from a local microalgae farm, Green Create Nutra, to be used as reference material for the evaluation of the current isolate. For each test, triplicates were performed with statistical analysis using one-way ANOVA.

\section{Total carbohydrates analysis}

To extract the carbohydrates from the biomass, acid hydrolysis was used as follows: $0.1 \mathrm{~g}$ of biomass was hydrolysed with $5 \mathrm{~mL}$ of sulphuric acid $(2 \mathrm{~N})$ and autoclaved at $120^{\circ} \mathrm{C}$ for $30 \mathrm{~min} .{ }^{15}$ The mixture was neutralised with solid sodium carbonate, diluted, centrifuged and filtered with a $0.2 \mu \mathrm{m}$ syringe filter. The total carbohydrates analysis was then performed using the phenol-sulphuric acid procedure. ${ }^{16}$

\section{Protein extraction and analysis}

Dried biomass $(5 \mathrm{mg})$ was weighed and mixed with $0.2 \mathrm{~mL}$ of $24 \%(\mathrm{w} / \mathrm{v})$ TCA in a microcentrifuge tube. ${ }^{17}$ The suspension was vortexed and incubated at $95^{\circ} \mathrm{C}$ for $15 \mathrm{~min}$. After cooling down to room temperature, $0.6 \mathrm{~mL}$ of distilled water was added. The tubes were centrifuged at $12,000 \mathrm{rpm}$ for $20 \mathrm{~min}$. The pellet was retained and resuspended in $0.5 \mathrm{ml}$ of Lowry reagent $\mathrm{D}$, prepared as 48:1:1 ratio of Lowry reagents $\mathrm{A}\left[2 \%(\mathrm{w} / \mathrm{v}) \mathrm{Na}_{2} \mathrm{CO}_{3}\right.$ (anhydrous) in $0.1 \mathrm{~N}$ $\mathrm{NaOH}] ; \mathrm{B}[1 \%(\mathrm{w} / \mathrm{v}) \mathrm{NaK}$ tartrate tetrahydrate $]$ and $\mathrm{C}[0.5 \%(\mathrm{w} / \mathrm{v})$ $\mathrm{CuSO}_{4} .5 \mathrm{H}_{2} \mathrm{O}$ in $\mathrm{H}_{2} \mathrm{O}$ ], respectively, and incubated for 3 hours at $55^{\circ} \mathrm{C}$. The suspension was centrifuged at $12,000 \mathrm{rpm}$ for $20 \mathrm{~min}$ and the supernatant was retained for protein quantification. ${ }^{18}$

\section{Lipids extraction}

The process of lipids extraction from the biomass was performed by solvent extraction for the treatment of microalgae biomass. ${ }^{19}$ The process was performed by mixing $1 \mathrm{~g}$ of dried biomass with $10 \mathrm{~mL}$ of chloroform:methanol $(2: 1 \mathrm{v} / \mathrm{v})$ and incubated in a shaker for 4 hour at $150 \mathrm{rpm}$. The suspension was then centrifuged for $5 \mathrm{~min}$ at $12,000 \mathrm{rpm}$. The supernatant was further filtered and then $4 \mathrm{~mL}$ of distilled water were added. The oil was separated as an organic phase in the bottom layer, which was collected in a bottle. A rotary evaporator was used to make the oil extract become solvent free at $60^{\circ} \mathrm{C}$ and the productivity in $\%$ was calculated. ${ }^{19}$ The crude oil was resuspended in $1 \mathrm{~mL}$ of methanol and stored at $4^{\circ} \mathrm{C}$ for further analysis.

\section{Fatty acids profiling}

Fatty acid quantification of the crude microalgae oil was determined by Gas Chromatography with Flame Ionization Detection (GC-FID) (Shimadzu model GC 2010) using the saponification process to get solvent-free methyl fatty acid sample. ${ }^{19}$ Exactly $1 \mu \mathrm{L}$ of the sample was injected in the GC column $\left(\mathrm{SP}^{\mathbb{}}{ }^{\mathrm{B}}-2560\right.$; fused silica, $100 \mathrm{~m} \times 0.25 \mathrm{~mm} \times 0.2 \mu \mathrm{m}$, Sigma-Aldrich). Helium was used as carrier gas at a split flow of $25.5 \mathrm{~mL} / \mathrm{min}$. The injector and detector temperatures were both at $250^{\circ} \mathrm{C}$. The injection took place at an initial oven temperature of $60^{\circ} \mathrm{C}$ maintained for $5 \mathrm{~min}$ and raised at a rate of $15^{\circ} \mathrm{C} / \mathrm{min}$ till $165^{\circ} \mathrm{C}$. This was maintained for $1 \mathrm{~min}$ and then raised to $225^{\circ} \mathrm{C}$ for $20 \mathrm{~min}$ at a rate of $2^{\circ} \mathrm{C} / \mathrm{min}$. Fatty Acid Methyl Esters (FAMEs) in the samples were identified through the comparison of their retention times against those of the standard FAME Mix 37 (Sigma-Aldrich). 


\section{Gas chromatography-mass spectrometry (GC/MS) analysis of fatty acid profiles}

Some of the signals from the GC analysis, which could not be identified, were further analysed by their mass spectra. The equipment and column used were Shimadzu and Phenomenex - ZB$5 \mathrm{MS}$ (phenyl arylene polymer, $30 \mathrm{~m} \times 0.25 \mathrm{~mm} \times 0.25 \mu \mathrm{m}$ ), respectively. The GC/MS was performed using the selected ion monitoring mode. The temperature monitoring program was oven temperature of $60^{\circ} \mathrm{C}$ maintained for $3 \mathrm{~min}$ and raised at a rate of $10^{\circ} \mathrm{C} / \mathrm{min}$ till $250^{\circ} \mathrm{C}$. Then raised to $300^{\circ} \mathrm{C}$ at a rate of $5^{\circ} \mathrm{C} / \mathrm{min}$. The identification was performed through comparison to the Wiley GC-MS Database library.

\section{Results}

\section{Microscopical diagnosis and phylogenetic analysis}

Isolate MD1 presented spherical/ovoid to cylindrical elongated cells, green in colour. The cells would form filaments consisting of 2 to 8 cells that could be broken easily (Figure 1). A pair of cells would share common mucilage presenting a parietal chloroplast each with one pyrenoid. During cell division, the elongating cells make a slight curvature. In terms of size, the cells would measure $6.47 \mu \mathrm{m} \pm 1.42 \times 5.00 \mu \mathrm{m} \pm 0.90$ (length $\mathrm{x}$ width).

Following the BLAST analysis, the isolate was found to be closely related to Rhexinema paucicellulare MF000570.1, MF034645.1 and MF034601.1 (100\% sequence similarity). The phylogenetic analysis, using sequences retrieved from NCBI, revealed that isolate MD1 clustered in the Rhexinema clade with strong bootstrap values (Figures 2 and 3). The phylogenetic analysis using the different methods also indicated 2 different clades in the Rhexinema genus corresponding to 2 different species (R.paucicellulare and $R$. sancta-tomeum).

\section{Analysis of growth pattern and biochemical composition of biomass}

The microalgae growth pattern was observed for a period of 22 days for 3 batches (replicates). A mean curve was drawn to illustrate the lag, exponential and early stationary phase (Figure 4). The culture was stopped at the late $\log$ phase at D21 resulting in a mean biomass production of $0.27 \pm 0.03 \mathrm{~g} / \mathrm{L}$. The carbohydrate yield between MD1 and Spirulina sp. was found to be significantly different $(p<0.05)$. The content of MD1 was recorded at $20.31 \% \pm 3.09$ while that of Spirulina sp. was recorded at $17.36 \% \pm 1.17$.

The mean protein content by dry weight was calculated at $25.71 \% \pm 2.96$ for MD1 as opposed to the $45.09 \% \pm 3.13$ for Spirulina sp. They were found to be significantly different between the isolate MD1 and Spirulina sp. $(\mathrm{p}<0.005)$. Based on the statistical analysis of the lipids content, it was observed that the content varied significantly between the two samples $(\mathrm{p}<0.05)$. The mean lipids content for MD1 was $13.88 \% \pm 3.86$ and was $5.86 \% \pm 1.74$ for Spirulina sp. The overall biochemical composition of the isolate $R$. paucicellulare MD1 and Spirulina sp. indicated significant differences between their primary metabolite contents (Figure 5).

\section{Analysis of fatty acids through GC and GC/MS}

The GC analysis of the extracts from MD1 and Spirulina sp. gave different FAME profiles and of different quantities (Table 1). However, certain compounds were common between them such as palmitic acid and linoleic acid based on the chromatograms obtained from each sample (Figure 6). From the MD1 lipid extract, the per- centage composition of the fatty acid (FA) groups varied considerably such as saturated FA (20.31\%), mono-saturated FA (5.69\%), polyunsaturated fatty acids (PUFAs) $(32.79 \%)$ and trans FA $(12.90 \%)$. Only a total composition of $71.69 \%$ of the compounds could be identified. The main FA in the lipids extracts were methyl esters of C16:0, C18:0, C18:1, C18:2n-6t, C18:2n-6 and C18:3.

The Spirulina sp. sample displayed a much higher content of saturated FA (63.64\%), mono-saturated FA (2.86\%) and PUFAs (30.84\%). Out of $100 \%$, only a total composition of $97.34 \%$ of the compounds could be identified. The main FA in the lipids extracts were methyl esters of C16:0, C16:1, C18:0, C18:1, C18:2n6 and C18:3. The individual profiles, compound identities and percentage composition are presented in Table 1.

The GC/MS analysis revealed the presence of more FA from both extracts. Sample MD1 displayed various FA from the omega-

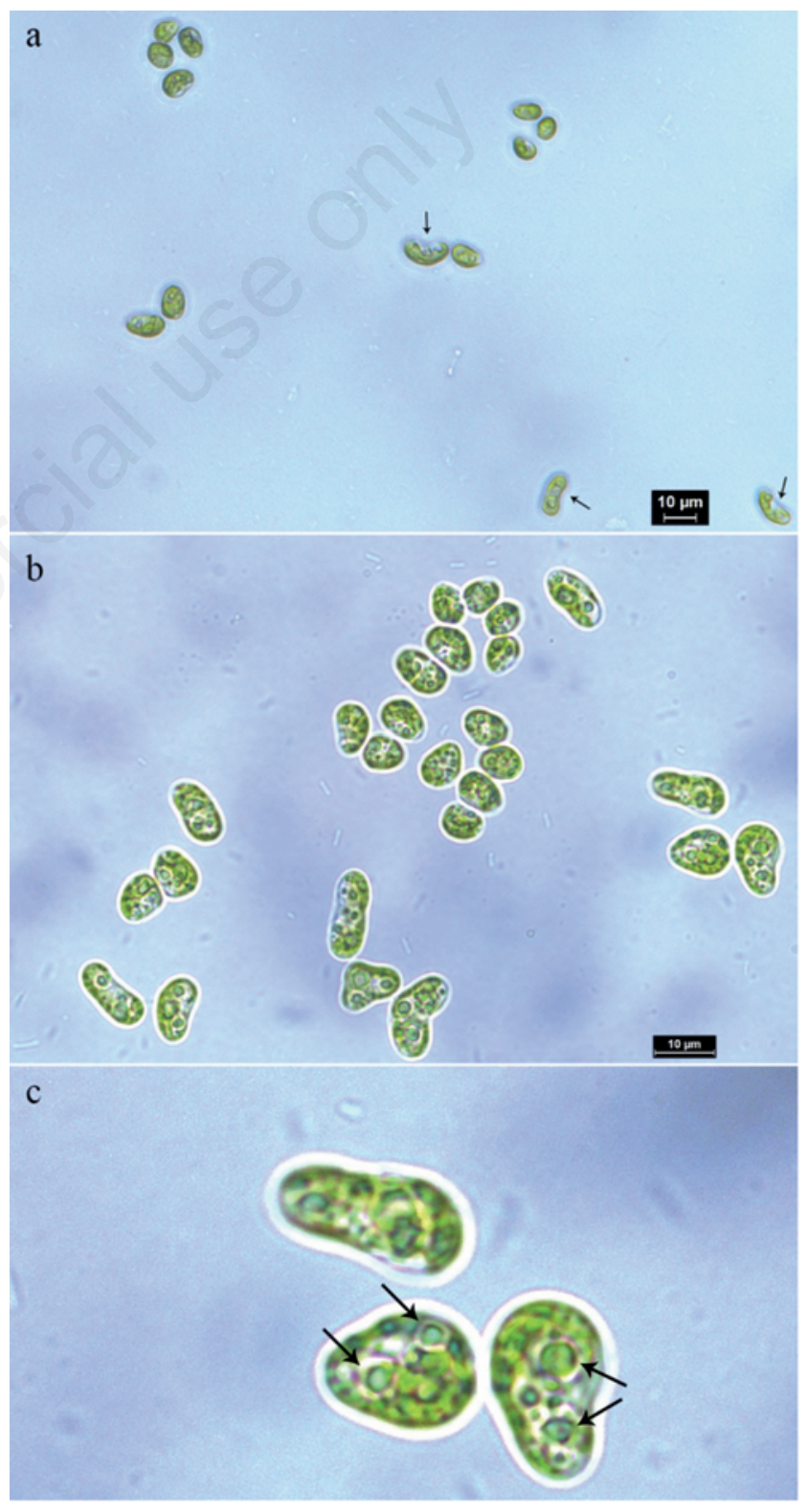

Figure 1. Morphology of isolate MD1: (a) Formation of elongated and slightly curved cells during division at $\times 400$ (small arrows); (b, c) Distinct singular pyrenoid observed per cell at x1000 magnification (larger arrows) with a parietal chloroplast. 
3 and omega-6 groups while the sample from Spirulina sp. did not possess any omega-3 FA. In the omega-3 class of FA, stearidonic acid, $\alpha$-linolenic acid, eicosapentaenoic acid and docosahexaenoic acid were identified in the MD1 extract while in the omega- 6 class, $\gamma$-linolenic acid, linoelaidic acid, linoleic acid and arachidonic acid were detected. However, GC/MS indicated the presence of $\gamma$ linolenic acid, linoleic acid and adrenic acid (docosatetraenoic acid) from the omega-6 FA class in Spirulina sp.

\section{Discussion}

\section{Isolate identification through microscopy and phylogeny}

Isolate MD1 presented a diagnosis that matched the descriptions of Rhexinema paucicellulare (Vischer) and Gloeotilopsis planctonica. $^{21}$ The strains described and deposited for both of these microalgae are available as SAG 463-1 and SAG 29.93,

Table 1. Fatty acids composition of the samples listed in order of their retention times and other $R$. paucicellulare strains available at the Culture Collection of Algae (Sammlung von Algenkulturen, SAG) at the University of Göttingen. ${ }^{20}$

\begin{tabular}{|c|c|c|c|c|}
\hline FAMEs composition (\%) & Spirulina sp. & MD1 & SAG463-1 & SAG 29.93 \\
\hline Palmitic acid (C16:0) & 49.48 & 18.17 & 13.11 & 15.80 \\
\hline Palmitoleic acid (C16:1) & 1.50 & - & - & 3.5 \\
\hline Hexadecadienoic acid (C16:2) & - & - & - & 12.5 \\
\hline Stearic acid (C18:0) & 14.17 & 2.14 & - & - \\
\hline Oleic acid (C18:1n-9) & 1.37 & 5.69 & 8.57 & 3.40 \\
\hline Linoelaidic acid (C18:2n-6t) & - & 12.90 & - & - \\
\hline Linoleic acid (C18:2n-6) & 17.40 & 6.31 & 6.30 & 36.40 \\
\hline$\alpha$-Linolenic acid (C18:3n-3) & - & 26.48 & 21.36 & 5.7 \\
\hline$\gamma$-Linolenic acid (C18:3n-6) & 13.44 & - & - & - \\
\hline Arachidonic acid (C20:4) & - & - & 4.33 & - \\
\hline Eicosapentaenoic acid (C20:5) & - & - & 8.05 & - \\
\hline Docosahexaenoic acid (C22:6) & - & - & - & - \\
\hline
\end{tabular}

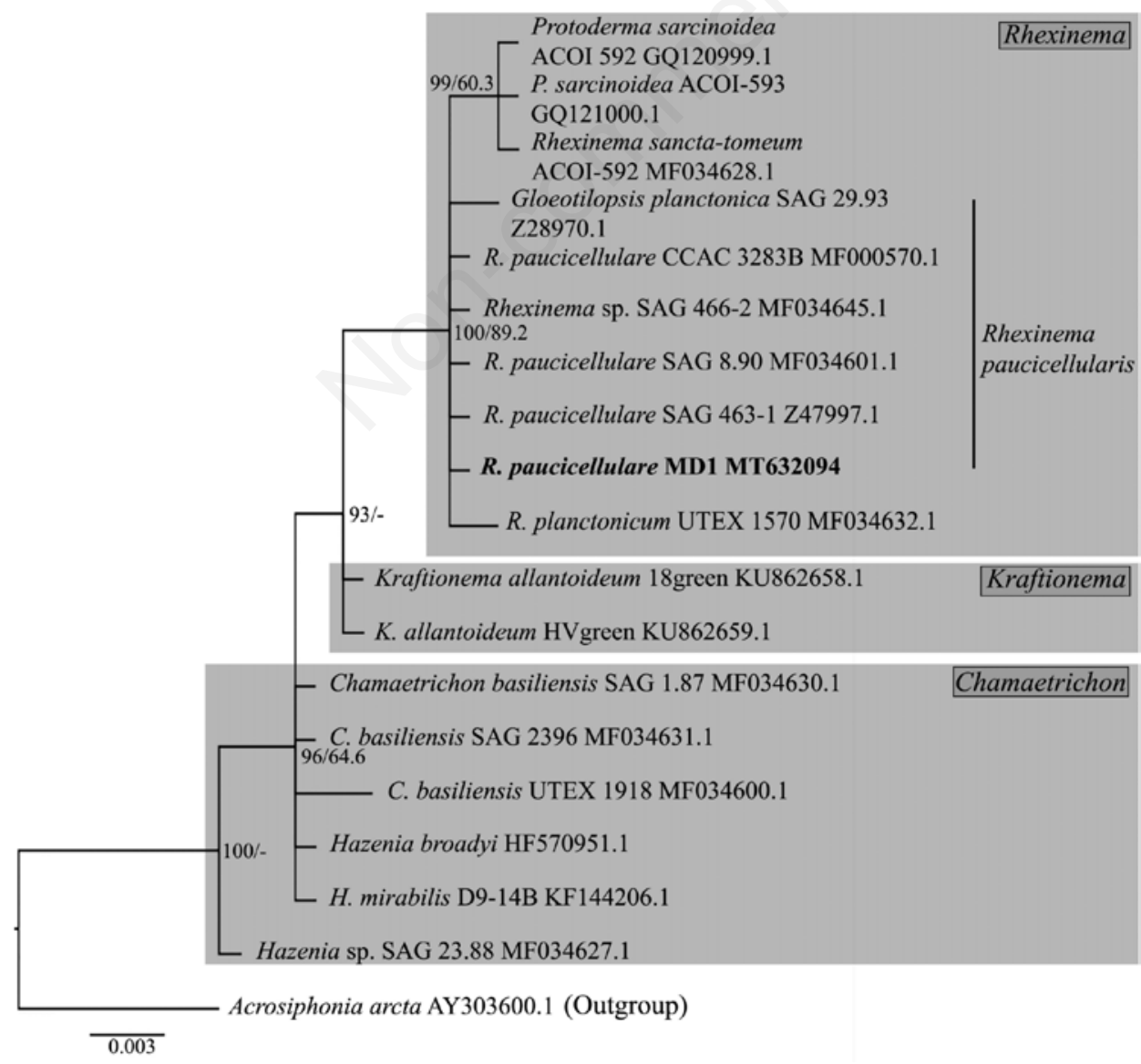

Figure 2. Molecular phylogeny of isolate MD1 based on $18 \mathrm{~S}$ rDNA sequences using Bayesian analysis and maximum likelihood. The phylogenetic tree was inferred by the AIC method with bootstrap support values indicated at the nodes and maximum likelihood (from left to right; values $<\mathbf{6 0 . 0} \%$ are not shown). The species in bold represent the newly sequenced isolate from Mauritius. 
respectively. However, the Rhexinema and Gloeotilopsis genus are very unstable due to various proposed combinations that are put forward following recent investigations. It appears that $G$. planctonica SAG 29.93 (Vischer) has been wrongly diagnosed. ${ }^{22}$

Recent research with the use of molecular tools coupled with microscopy, indicated that G. planctonica SAG 29.93 was confirmed to be $R$. paucicellulare. ${ }^{5}$ Our phylogenetic analysis indicat- ed that both strains SAG 463-1 and SAG 29.93 strongly clustered together, in accordance to other studies, ${ }^{5,6}$ with isolate MD1, which was thus confirmed to be $R$. paucicellulare. However, the analysis also indicated a separate clade containing $R$. santa-tomea Darienko et Pröschold sp. nov. and Protoderma sarcinoidea (Groover et Bold).

Darienko and Pröschold, ${ }^{5}$ have recently proposed $R$. santa-

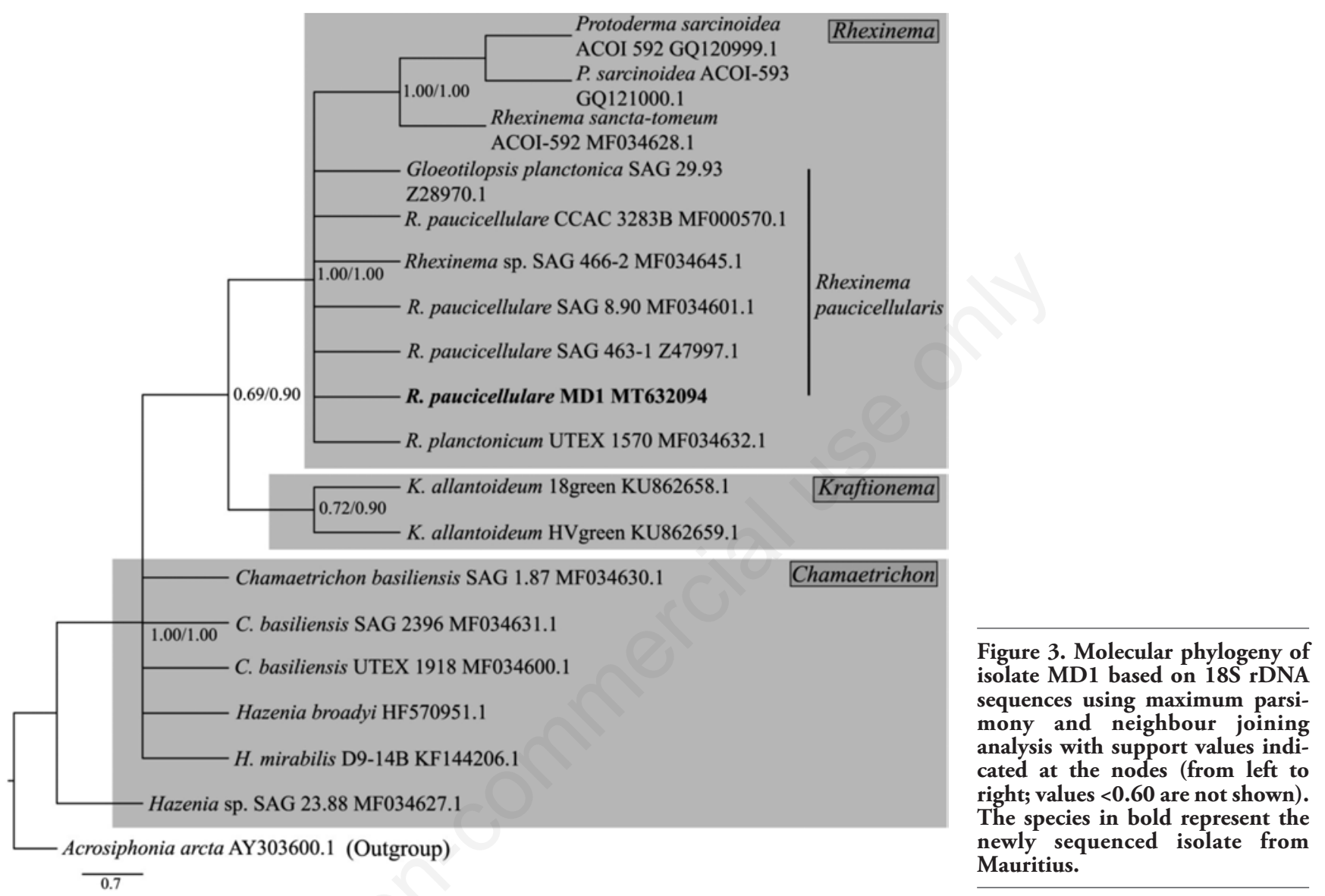

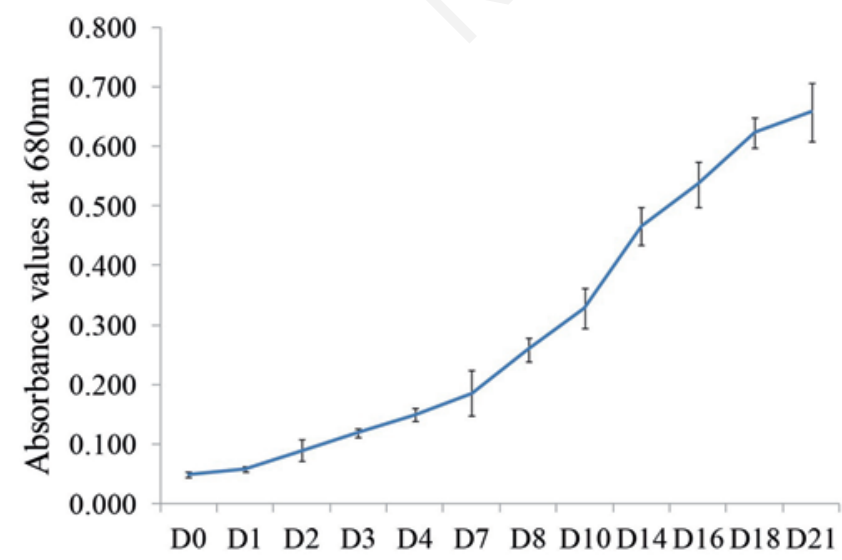

Days of culture

Figure 4. Average growth curve for isolate MD1 for a period of 22 days.

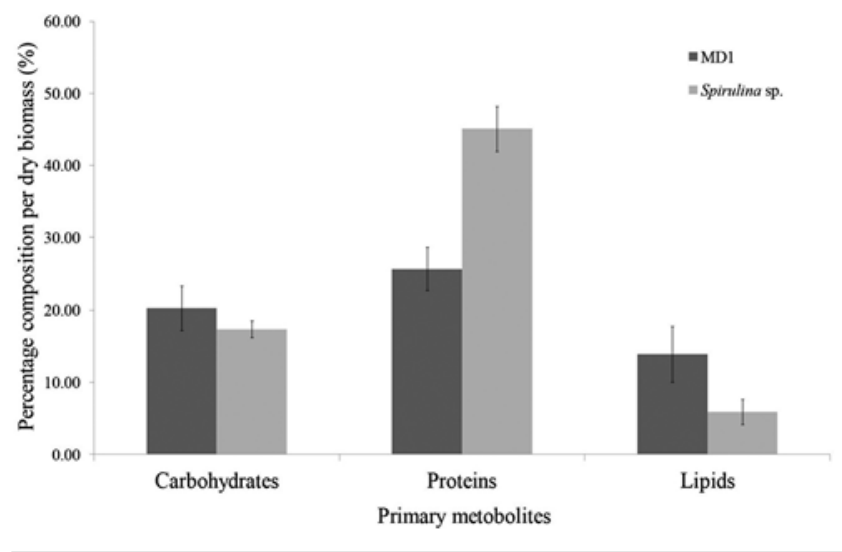

Figure 5. Overall biochemical composition of $R$. paucicellulare MD1 and Spirulina sp. 
tomea as a new species and transferred Protoderma sarcinoidea (Groover et Bold) to Rhexinema sarcinoidea (Groover et H. C. Bold) Darienko et Pröschold combinatio nova. Škaloud et al. ${ }^{5}$ do not accept these new proposals as taxonomically, Pleurastrum was named before Rhexinema and therefore considered the need for revising the type strains for both Pleurastrum and Rhexinema. This kind of situation highlights the significance of identification of microalgae through DNA based markers along with morphological characterisation.

\section{Carbohydrate content}

Spirulina sp. was used as a positive control to be able to determine the biochemical value of the isolated microalgae as this particular strain was intensively cultured to be used as a nutraceutical product and feed additive. Other Spirulina sp.-based studies have shown levels as low as $14.94 \% \pm 3.20$ and as high as $58.17 \% \pm 3.70$ under specific conditions. ${ }^{23}$ However, for isolate MD1 which was better than Spirulina sp., it is difficult to compare it to other members of its genus due to a lack of data in this regard but was found to be satisfactory in comparison to other microalgae such as Dunaliella tertiolecta, Chlorella vulgaris and Nannochloropsis sp. $\left(46.5 \% \pm 4.5,55.6 \% \pm 4.3\right.$ and $54.9 \% \pm 5.0$, respectively). ${ }^{24}$

Furthermore, light intensity is also important in the production and accumulation of carbohydrates. ${ }^{25}$ The contents of Chlorella sp. PTCC 6010 increased from $10.69 \%$ to $49.82 \%$ when the light intensity was increased from 60 to $255 \mu \mathrm{mol}$ photons $\mathrm{m}^{-2} \mathrm{~s}^{-1}$. In the current study, the light intensity could have led to a lower carbohydrate content than the true potential of the isolate. Therefore, isolate $R$. paucicellulare MD1 should not yet be ruled out as a potential carbohydrate enriched microalgae.

\section{Protein content}

The protein content of Spirulina sp. was recorded at an appropriate, if not a minimum, amount for this microalgae as it is considered as one of the richest sources of protein. However in comparison to isolate MD1, the protein content was half that of Spirulina sp. Microalgae such as Dunaliella sp., Tetraselmis sp. and Nannochloropsis sp. were found to produce levels of proteins equivalent to $12.26 \%, 4.83 \%$ and $13.00 \%$ respectively and are actively used as sources of feed for aquaculture. ${ }^{17,26}$ Microalgae from the genus Rhexinema have not yet been studied in terms of protein content, although MD1 showcases appropriate levels as a Chlorophyte.

\section{Lipid content analysis}

Between the two investigated microalgae, Spirulina sp. showed the lowest lipid contents. Other research has indicated values of $4-9 \%$ for Spirulina sp. ${ }^{27}$ More recent investigations have shown maximum yields of $9 \%$ from Spirulina platensis in an attempt of identifying potential candidates for biodiesel production. ${ }^{28}$ In the case of isolate MD1, the lipid contents were significantly higher than that of Spirulina sp. However, lipid content
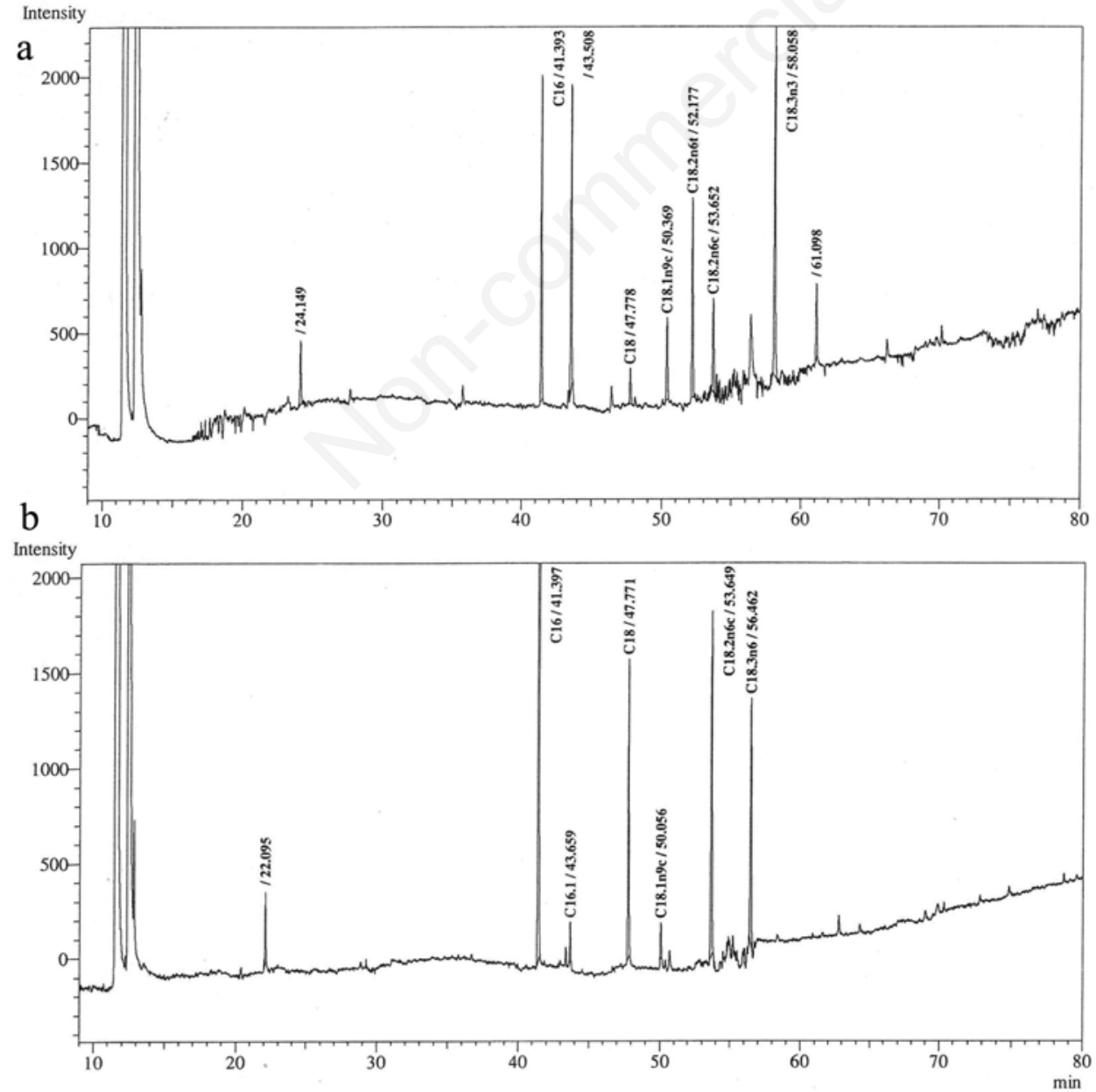

Figure 6. Fatty acid profile chromatograms of (a) isolate MD1 and (b) Spirulina sp. 
analysis for this species or even genus is not available although only the fatty acid profile of $R$. paucicellulare SAG 463-1 and SAG 29.93 have been examined. ${ }^{20}$

Nonetheless, other microalgae such as Scenedesmus obliquus and Chlorella vulgaris are used in the production of lipids as they can yield up to $14 \%$ and $22 \%$ of lipids, respectively. ${ }^{29}$ Strains of $S$. obliquus were found to produce $39.73 \%$ of lipids under normal culture conditions. ${ }^{30} \mathrm{~N}$. salina CCMP1176 yielded a lipid content of $36.95 \% \pm 0.91$ while $N$. granulata CCMP525 yielded a content of $60.35 \% \pm 1.20 .^{31}$

However, it should be noted that light intensity has considerable influence on how microalgae can produce and/or increase lipids. ${ }^{32}$ Scenedesmus sp. was found to produce a lipid content of $41.1 \%$ and a neutral lipid content of $32.9 \%$ when the light intensity was increased from 250 to $400 \mu \mathrm{mol}$ photons $\mathrm{m}^{-2} \mathrm{~s}^{-1}$. 33 Therefore, although every microalgae will have a certain upper and lower limit, hypothetically, the value reported in this project may not be representative of the real capacity of isolate $R$. paucicellulare MD1.

\section{Fatty acids profiles analysis}

The fatty acid profile of isolate MD1 and Spirulina sp. displayed variations in terms of their content and composition. The FA found in Spirulina sp. was found to contain a high level of palmitic acid in comparison to the other FA. Among the PUFAs, the presence of linoleic acid and $\gamma$-linolenic acid was confirmed and this type of FA profile is typical in Spirulina sp. strains. ${ }^{34}$ The GC/MS analysis did not indicate the presence of any omega-3 FA. However, the presence of other omega- 6 fatty acids such as docosatetraenoic acid was revealed but was not detected in the GC analysis, which could be due to a low concentration.

Isolate MD1 presented a different profile with lower palmitic acid content. Furthermore, $\alpha$-linolenic acid was quantified at $26.48 \%$ instead of $\gamma$-linolenic acid in the GC although the latter was also detected through GC/MS, which was indicative of a very low concentration. The occurrence of these PUFAs is a known observation in freshwater microalgae. It should be noted that marine microalgae have a tendency to produce more eicosapentaenoic acid and docosahexaenoic acid while freshwater species produce more $\gamma$-linolenic acid and $\alpha$-linolenic acid. ${ }^{27}$ Freshwater species such as Chlorella vulgaris and Spirulina sp. platensis were found to be abundant in $\gamma$-linolenic acid $(1.9 \mathrm{~g} / 100 \mathrm{~g})$ and $\alpha$ linolenic $(2.8 \mathrm{~g} / 100 \mathrm{~g})$, respectively, while marine species such as Nannochloropsis oculata and Phaeodactylum tricornutum possessed higher levels of eicosapentaenoic acid and docosahexaenoic acid. ${ }^{27}$ Furthermore, data is scarce on the Rhexinema genus when it comes to fatty acids profiling.

The only study retrieved so far evaluated the strains for this genus, SAG 463-1 and SAG 29.93. ${ }^{20}$ Their respective profiles were compared to isolate MD1 (Table 1). Strain 463-1 shared a close profile to MD1 than with SAG 29.93. Significant differences could be observed by the content of $\gamma$-linolenic acid and $\alpha$-linolenic acid. Additionally, the occurrence of linoelaidic acid was quite surprising as this trans fatty acid has only been detected in the microalgae Trachelomonas similis. ${ }^{20}$ The same authors concluded that FA profiles of closely related species would show variations as shown here. ${ }^{20}$ However, the presence of these PUFAs is still encouraging as they are highly required in aquaculture practices and feed diets, especially eicosapentaenoic acid and docosahexaenoic acid. Although they were detected at low levels in isolate MD1, it should be noted that the lipid content and FA profile resulted from culture under specific conditions and that the contents may change under stress conditions. Therefore, further experiments would be required to assess the maximum productivity of isolate $R$. paucicellulare MD1.

\section{Conclusions}

The findings on $R$. paucicellulare MD1 showed adequate levels of carbohydrate and proteins in comparison to other microalgae and this data would be the first report of its kind for this particular species. The lipid and fatty acid profile also indicated suitable contents of $\alpha$-linolenic acid and the presence of other PUFAs such as eicosapentaenoic and docosahexaenoic, which are highly demanded in aquaculture practices. However, the current biochemical profile of this isolate was obtained under specific conditions where the light intensity was identified as a limiting factor, which could have influenced the current findings. Further investigations involving stress conditions such as high light conditions, influence of temperature and nutrient starvation would help understand the lower and upper limits of its biochemical composition.

\section{References}

1. Brunchault RV, Soulange JG, Sanmukhiya VMR, Sevathian JC. Molecular and bioactive profiling of selected Eugenia species from Mauritius Island. Int J Plant Biol 2014;5:4728

2. Sathasivam R, Radhakrishnan R, Hashem A, Abd-Allah EF. Microalgae metabolites: A rich source for food and medicine. Saudi J Biol Sci 2019;26:709-22.

3. Ballah M, Bhoyroo V, Neetoo H. Assessment of the physicochemical quality and extent of algal proliferation in water from an impounding reservoir prone to eutrophication. J Ecol Environ 2019;43:5.

4. Sadally SB, Taleb-Hossenkhan N, Bhagooli R. Microalgal distribution, diversity and photo-physiological performance across five tropical ecosystems around Mauritius Island. West Indian Ocean J Mar Sci 2016;15.

5. Darienko T, Pröschold T. Toward a monograph of non-marine Ulvophyceae using an integrative approach (Molecular phylogeny and systematics of terrestrial Ulvophyceae II.). Phytotaxa 2017;324:1.

6. Škaloud P, Rindi F, Boedeker C, Leliaert F. Freshwater Flora of Central Europe, Vol 13: Chlorophyta: Ulvophyceae (Süßwasserflora von Mitteleuropa, Bd. 13: Chlorophyta: Ulvophyceae). Berlin, Heidelberg: Springer Berlin Heidelberg; 2018.

7. Maneeruttanarungroj C, Incharoensakdi A. Rapid method for DNA isolation from a tough cell wall green alga Tetraspora sp. CU2551. World J Microbiol Biotechnol 2016;32:99.

8. Bérard A, Dorigo U, Humbert JF, Martin-Laurent F. Microalgae community structure analysis based on $18 \mathrm{~S}$ rDNA amplification from DNA extracted directly from soil as a potential soil bioindicator. Agron Sustain Dev 2005;25:285-91.

9. Katoh K, Rozewicki J, Yamada KD. MAFFT online service: multiple sequence alignment, interactive sequence choice and visualization. Brief Bioinform 2019 19;20:1160-6.

10. Darriba D, Taboada GL, Doallo R, Posada D. jModelTest 2: more models, new heuristics and parallel computing. Nat Methods 2012;9:772.

11. Guindon S, Dufayard J-F, Lefort V, et al. New algorithms and methods to estimate maximum-likelihood phylogenies: assessing the performance of PhyML 3.0. Syst Biol 2010;59:307-21.

12. Ronquist F, Teslenko M, van der Mark P, et al. MrBayes 3.2: Efficient bayesian phylogenetic inference and model choice across a large model space. Syst Biol 2012;61:539-42. 
13. Abomohra AE-F, Wagner M, El-Sheekh M, Hanelt D. Lipid and total fatty acid productivity in photoautotrophic fresh water microalgae: screening studies towards biodiesel production. J Appl Phycol 2013;25:931-6.

14. Griffiths MJ, van Hille RP, Harrison STL. Lipid productivity, settling potential and fatty acid profile of 11 microalgal species grown under nitrogen replete and limited conditions. J Appl Phycol 2012;24:989-1001.

15. Miranda JR, Passarinho PC, Gouveia L. Pre-treatment optimization of Scenedesmus obliquus microalga for bioethanol production. Bioresour Technol 2012;104:342-8.

16. Dubois M, Gilles KA, Hamilton JK, et al. Colorimetric method for determination of sugars and related substances. Anal Chem 1956;28:350-6.

17. Slocombe SP, Ross M, Thomas N, et al. A rapid and general method for measurement of protein in micro-algal biomass. Bioresour Technol 2013;129:51-7.

18. Lowry OH, Rosebrough NJ, Farr AL, Randall RJ. Protein measurement with the Folin phenol reagent. J Biol Chem 1951;193:265-75.

19. Santhosh Kumar K, Prasanthkumar S, Ray JG. Experimental assessment of productivity, oil-yield and oil-profile of eight different common freshwater-blooming green algae of Kerala. Biocatal Agric Biotechnol 2016;8:270-7.

20. Lang I, Hodac L, Friedl T, Feussner I. Fatty acid profiles and their distribution patterns in microalgae: a comprehensive analysis of more than 2000 strains from the SAG culture collection. BMC Plant Biol 2011;11:124.

21. Sluiman HJ. Cell division in Gloeotilopsis planctonica, a newly identified Ulvophycean alga (Chlorophyta) studied by freeze fixation and freeze substitution. J Phycol 1991;27:291-8.

22. Friedl T. Evolution of the polyphyletic genus Pleurastrum (Chlorophyta): inferences from nuclear-encoded ribosomal DNA sequences and motile cell ultrastructure. Phycologia 1996;35:456-69.

23. Vieira Salla AC, Margarites AC, Seibel FI, et al. Increase in the carbohydrate content of the microalgae Spirulina in culture by nutrient starvation and the addition of residues of whey protein concentrate. Bioresour Technol 2016;209:133-41.

24. Efremenko EN, Nikolskaya AB, Lyagin IV, et al. Production of biofuels from pretreated microalgae biomass by anaerobic fermentation with immobilized Clostridium acetobutylicum cells. Bioresour Technol 2012;114:342-8.

25. Samiee-Zafarghandi R, Karimi-Sabet J, Abdoli MA, Karbassi A. Increasing microalgal carbohydrate content for hydrothermal gasification purposes. Renew Energy 2018;116:710-9.

26. Andreotti V, Solimeno A, Chindris A, et al. Growth of Tetraselmis suecica and Dunaliella tertiolecta in aquaculture wastewater: numerical simulation with the BIO_ALGAE model. Water Air Soil Pollut 2019;230:60.

27. Matos ÂP, Feller R, Moecke EHS, et al. Chemical characterization of six microalgae with potential utility for food application. J Am Oil Chem Soc 2016;93:963-72.

28. Kalsum L, Dewi E, Margarety E, Ningsih AS. Lipid extraction from microalgae Spirulina platensis for raw materials of biodiesel. J Phys Conf Ser 2019;1167:012051.

29. Demirbas A. Use of algae as biofuel sources. Energy Convers Manag 2010;51:2738-49.

30. Cuéllar-García DJ, Rangel-Basto YA, Urbina-Suarez NA, et al. Lipids production from Scenedesmus obliquus through carbon/nitrogen ratio optimization. J Phys Conf Ser 2019; 1388:012043.

31. Ma Y, Wang Z, Yu C, et al. Evaluation of the potential of 9 Nannochloropsis strains for biodiesel production. Bioresour Technol 2014;167:503-9.

32. Aratboni HA, Rafiei N, Garcia-Granados R, et al. Biomass and lipid induction strategies in microalgae for biofuel production and other applications. Microb Cell Factories 2019;18:178.

33. Liu J, Yuan C, Hu G, Li F. Effects of light intensity on the growth and lipid accumulation of microalga Scenedesmus sp. 11-1 under nitrogen limitation. Appl Biochem Biotechnol 2012;166:2127-37.

34. Mühling M, Belay A, Whitton BA. Variation in fatty acid composition of Arthrospira (Spirulina) strains. J Appl Phycol 2005; 17:137-46. 